\title{
STATIC STRUCTURAL ANALYSIS OF SUSPENSION ARM USING FINITE ELEMENT METHOD
}

\author{
Jagwinder Singh ${ }^{1}$, Siddhartha Saha ${ }^{2}$ \\ ${ }^{1}$ Student, Mechanical Engineering, BBSBEC, Punjab, India \\ ${ }^{2}$ Assistant Professor, Mechanical Engineering, BBSBEC, Punjab, India
}

\begin{abstract}
The function of suspension system is to absorb vibrations due to rough terrains or road disturbances and to provide stability under circumstances like accelerating, cornering, uneven road, braking, loading and unloading etc. Control arm is one of the most important part of the suspension system, as it joins the steering knuckle to the vehicle frame. Also suspension arm is responsible for up and down movement of wheels when hitting bumps. It is also designed to maximize the friction between tire contacts, patch the road surface to provide vehicle stability under any circumstances. It can be seen in many types of the suspensions like wishbone or double wishbone suspensions. Many times it is also called as A-type control arm. In this study control arm was reverse engineered. Reverse engineering refers to the process of obtaining a CAD model from an existing physical part. CAD model was prepared using CATIA v5 software and finite element analysis was done using ANSYS 14.5 software by importing the parasolid file to ANSYS. The model is subjected to loading and boundary conditions and then analyzed using the FEA techniques. The static structural analysis was done to find out the stress, deformation and safety factor of component. The model was meshed using 10-noded tetrahedral elements. Result obtained from the analysis were studied to check whether the design is safe or not. In some cases the stresses becomes more than safe limit. In that case optimization approach is carried out to increase the structural strength of the component. In this case maximum von-misses stress is $211 \mathrm{MPa}$ which is below the yield strength of the material.
\end{abstract}

Keywords - Suspension System, Control Arm, FEA analysis, Reverse Engineering $* * *$

\section{INTRODUCTION}

The lower suspension arm are connected to the vehicle frame with bushing and permits the wheel to go up and down in response to the road surface. Control arm is the most crucial part of the suspensions system. It is made from materials like steel, iron or aluminum. Suspension arm is very important for the all vehicles on the road, if there is no suspension arm in suspension system, then it is expected that it can result in annoying vibrations and unwanted driving irregularities that could sometimes lead to road accidents like collisions with another car or obstruction on the road. Suspension arm is one of the most important component in the suspension system. It is fitted in various types of the suspensions like Macpherson, wishbone or double wishbone suspensions. During actual working conditions the maximum load is transferred from tire to the ball joint in Macpherson strut system and in double wishbone maximum load is transferred from upper arm to the lower arm which is responsible for the failure and twisting of lower suspension arm at the ball joint locations as well as control arm because of more impact load. Hence it essential to focus on the stress and deformation study of lower suspension arm to develop and the changes in existing design. The FEA approach is used for analysis of a suspension link for static and Von-Mises stress analysis of lower suspension arm. Analysis is to be done considering the Gross vehicle weight. As stress is higher than safe limit or yield strength some geometric changes adopted in design to make it safe.

\section{OBJECTIVES}

The aim of the project is to FEM analysis of lower arm. Following are the main objectives of project-

- Manual reverse engineering of the suspension arm

- Making a 3D solid parametric model of suspension link in CATIA software

- Meshing the model by 10 noded tetrahedral elements in ANSYS

- $\quad$ Static analysis to find Von-Mises stresses

- Static analysis deformation plot in ANSYS

- If fails corrective actions for design improvement of suspension link.

\section{PROBLEM DEFINITION}

Due to the many functions control arm is main part in components of suspension system. As vehicle goes through speed breaker, bumps etc. and many other kinds of forces transmitted from the car wheels which are transferred to control arm via ball joint assembly to the wheel. Force values are mentioned in the load case. So in this study the key concern is to discover the maximum stress section and stress value in control arm and relate these values with tensile yield strength of material.

\section{METHODOLOGY}

To solve the problem mentioned above we have used the methodology. We have first manually reverse engineered 
the lower suspension arm with the help of special tools like Vernier gauge, radius gauge and divider etc. All the dimensions which are measured have been recorded on the drawing. Now by taking the dimensions from the drawing modelling of lower suspension arm is done in CATIA software. After modelling the lower suspension arm, we have import the IGES file to the ANSYS which is FEA software by using this software we have to solve the problem.

Further we have to mesh the model by using the 10 noded tetrahedral elements. Tetra elements give improved results as compared to other type of elements, therefore tetrahedral elements were used. In further step we have to apply the loads i.e. forces and toques which are mentioned in the load cases. The material used was mild steel. After the material had applied we have to apply the boundary conditions according the actual working conditions i.e. where it fixed and where it is free. After that problem have to be solved by using ANSYS software. In the next step we have to solve the model in the analysis phase. The results are compared if the results are satisfied then problem is solved and if not then editing of model is done and again the steps should be followed.

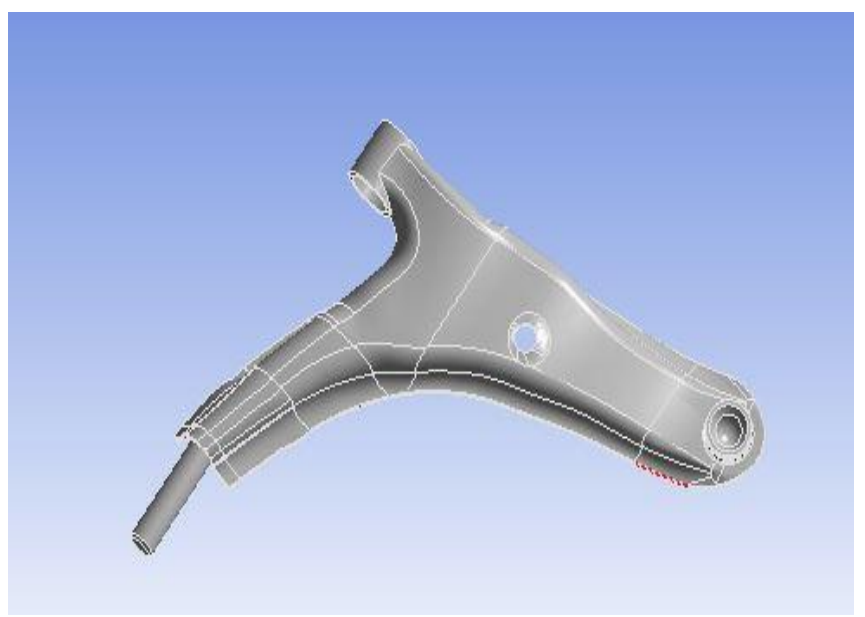

Fig-4.1: Solid Model

In following table particular conditions are shown in Table 4 for the typical component.

Table4: Vehicle Specification

\begin{tabular}{|l|l|}
\hline Wheel Base & $2365 \mathrm{~mm}$ \\
\hline Overall Length & $4095 \mathrm{~mm}$ \\
\hline Overall Width & $1575 \mathrm{~mm}$ \\
\hline Overall Height & $1395 \mathrm{~mm}$ \\
\hline Ground Clearance & $170 \mathrm{~mm}$ \\
\hline Turning Radius & $4.8 \mathrm{~mm}$ \\
\hline Unladed Weight & $870 \mathrm{Kg}$ \\
\hline Laden Weight & $1315 \mathrm{Kg}$ \\
\hline
\end{tabular}

Table4: Assumptions made for calculations

\begin{tabular}{|l|l|}
\hline Force & $2520 \mathrm{~N}$ \\
\hline Material & Mild Steel \\
\hline Density & $7870 \mathrm{~kg} / \mathrm{m}^{3}$ \\
\hline
\end{tabular}

\begin{tabular}{|l|l|}
\hline Young's modulus & $2 * 10^{11} \mathrm{~Pa}$ \\
\hline Tensile strength & $245 \mathrm{MPa}$ \\
\hline Poisson's ratio & 0.29 \\
\hline
\end{tabular}

\section{STATIC ANALYSIS}

\subsection{Introduction}

The control arm bushing consist of two types of bushings, a durable rubber bushing and inner metal sleeve. The bushing acts as hinged Damper to support the suspension and provide a more controllable and comfortable ride.

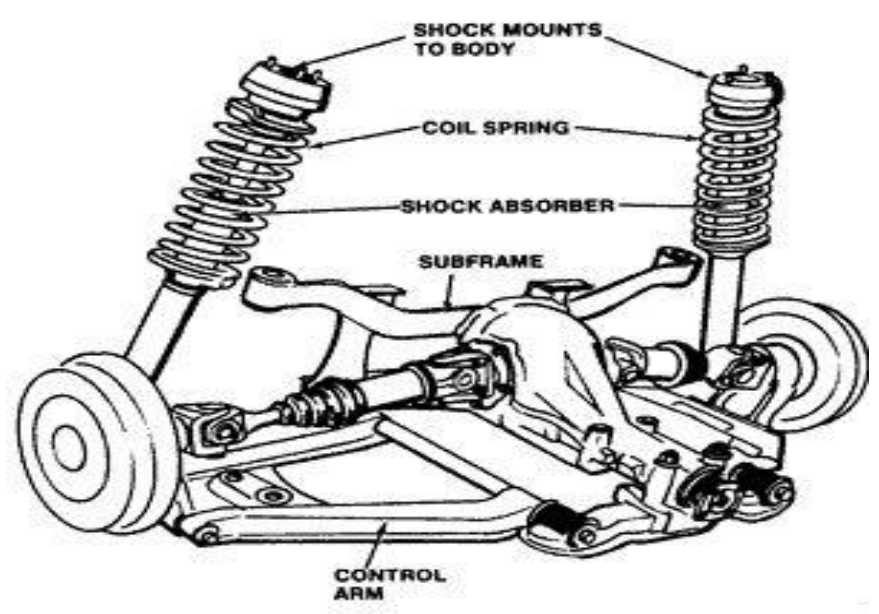

Fig-5.1.1 General Suspension System

The bushings are attached to the chassis or the frame of the vehicle and the ball joint is attached to the wheel of the vehicle.

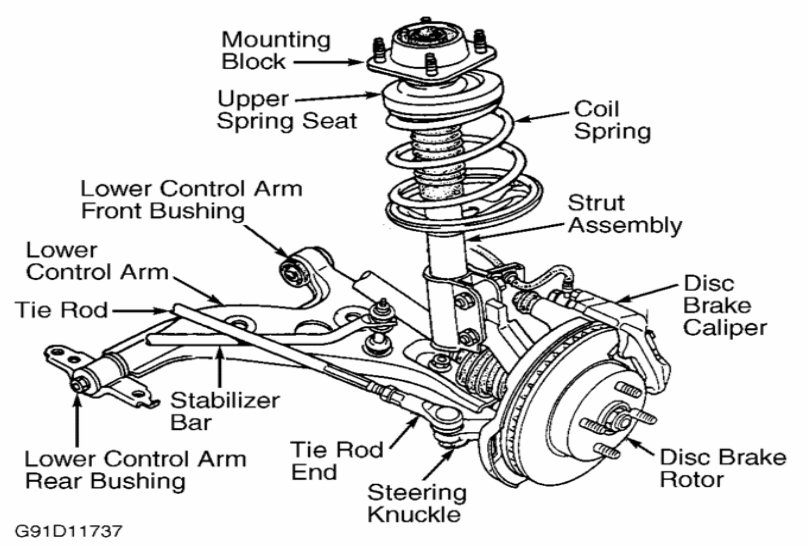

Fig 5.1.2 MacPherson Suspension System

\subsection{D Model of Control Arm}

Control arm is first modeled in CATIA software which is outstanding CAD software. CATIA is very user friendly software which makes modeling so easy. 


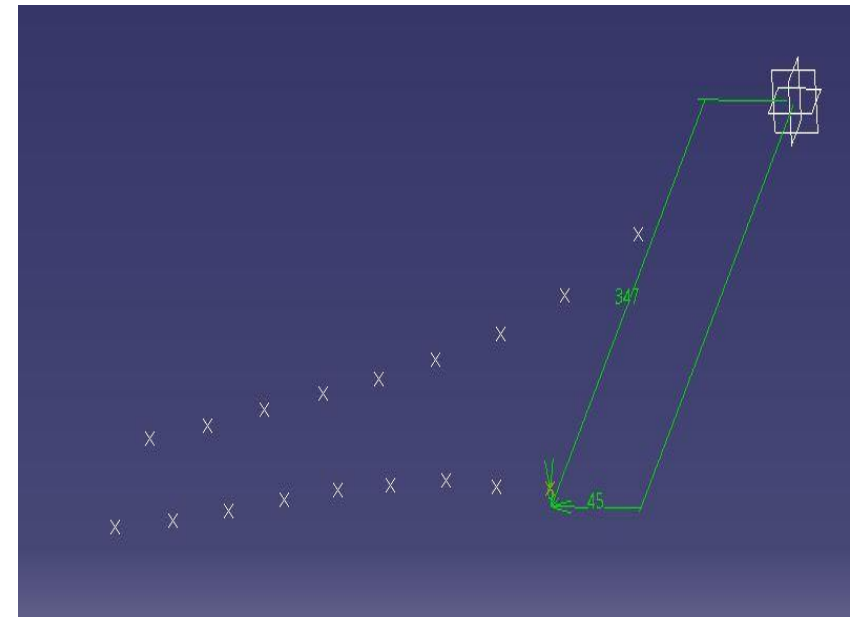

Fig 5.2.1 Drawing Reference Points

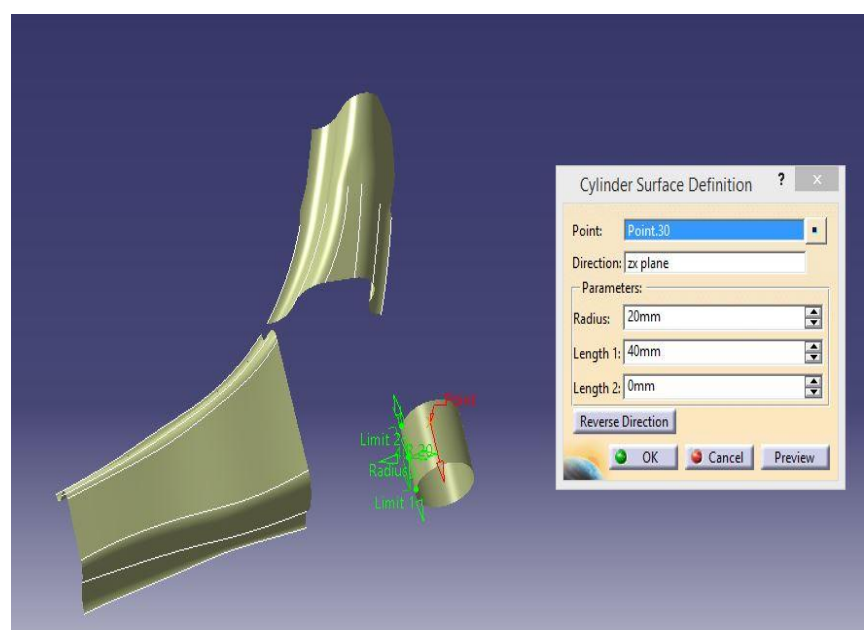

Fig 5.2.2 Sketching the Front Bushing

\subsection{Mesh Generation}

In this analysis mesh generation is auto generation by the ANSYS software, after that sizing of $5 \mathrm{~mm}$ was given to the suspension arm. Tetrahedral 10-noded elements were used to mesh the lower suspension arm.

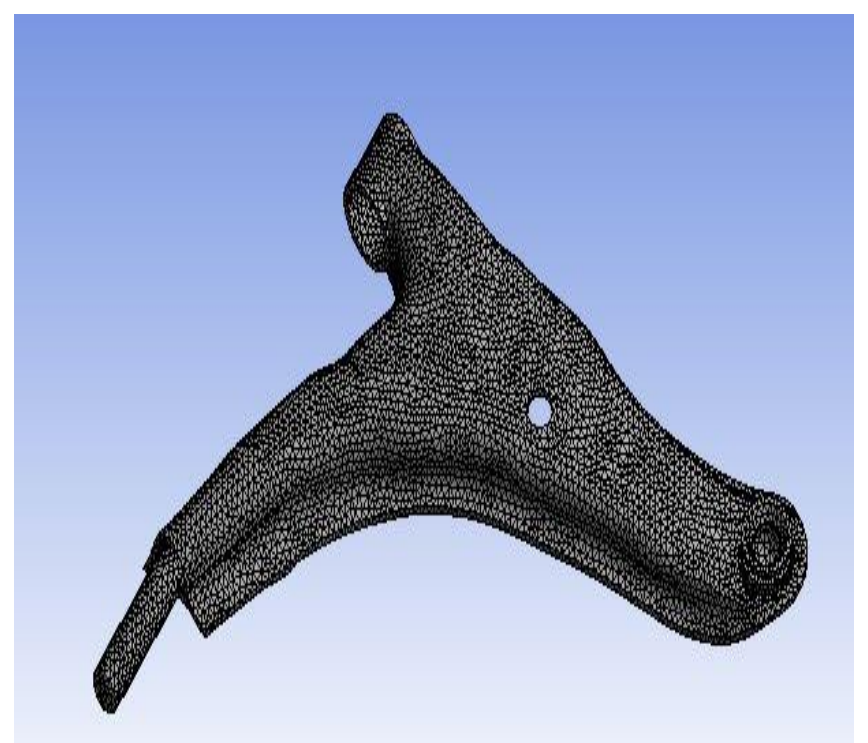

Fig 5.3 Mesh Model $>\quad$ No of Nodes -9634

$>\quad$ No of Elements- 34175

$>$ Element Type - Tetrahedral (10 node)

\subsection{Loading and Boundary Conditions}

\subsubsection{Static Loads on the Vehicle}

Weight of vehicle acting at its center of gravity

$$
\mathrm{G}=\mathrm{m} \cdot \mathrm{g}
$$

As we know approximately $0.39 \%$ of weight of the whole body or car is carried by front wheels and $0.61 \%$ weight carried by rear wheels.

So reaction equations are-

Reaction on front wheels $\left(\mathrm{R}_{1}\right)=0.39 * \mathrm{G}$

Reaction on rear wheels $\left(\mathrm{R}_{2}\right)=0.61 * \mathrm{G}$

So equation becomes-

$$
\mathrm{R}_{1} \mathrm{~S}_{1}=\mathrm{R}_{2} \mathrm{~S}_{2}
$$

As we know

$$
\mathrm{S}=\mathrm{S}_{1+} \mathrm{S}_{2}
$$

Loads on front axle and rear axle are found by using the equilibrium equation-

$$
\begin{gathered}
\mathrm{G}_{\mathrm{FA}}=\mathrm{G}^{*} \mathrm{~S}_{2} / \mathrm{S} \\
\mathrm{G}_{\mathrm{RA}}=\mathrm{G}^{*} \mathrm{~S}_{1} / \mathrm{S}
\end{gathered}
$$

Static load on one wheel of the front wheel-

$$
\mathrm{G}_{\mathrm{FAW}}=\mathrm{G}_{\mathrm{FA}} / 2
$$

\section{Table 5.4}

\begin{tabular}{|l|l|}
\hline Parameters & Description \\
\hline $\mathrm{G}$ & Weight of vehicle acting at $\mathrm{CG}$ \\
\hline $\mathrm{m}$ & Mass \\
\hline $\mathrm{G}$ & Acceleration due to gravity \\
\hline $\mathrm{R}_{1}$ & Reaction on front wheels \\
\hline $\mathrm{R}_{2}$ & Reaction on rear wheels \\
\hline $\mathrm{S}_{1}$ & Distance between CG and front axel \\
\hline $\mathrm{S}_{2}$ & Distance between CG and rear axel \\
\hline $\mathrm{S}$ & Wheel base \\
\hline $\mathrm{G}_{\mathrm{FA}}$ & Loads on front axel \\
\hline $\mathrm{G}_{\mathrm{RA}}$ & Loads on rear axel \\
\hline $\mathrm{G}_{\mathrm{FAW}}$ & Loads on one wheel of front axel \\
\hline
\end{tabular}

Loads are in form of force values and moments. The boundary conditions applied on the component. 


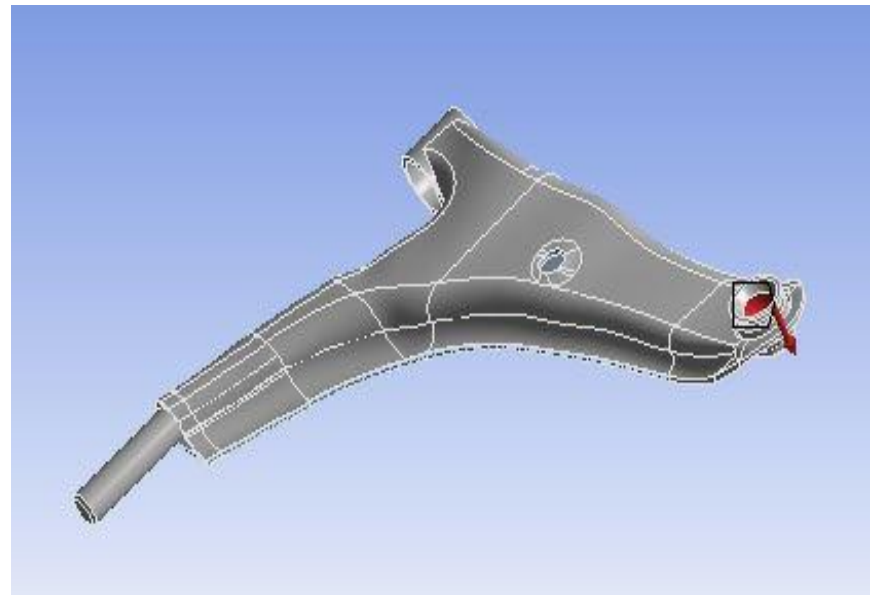

Fig 5.4.1 Loading Condition

\subsubsection{Boundary Conditions}

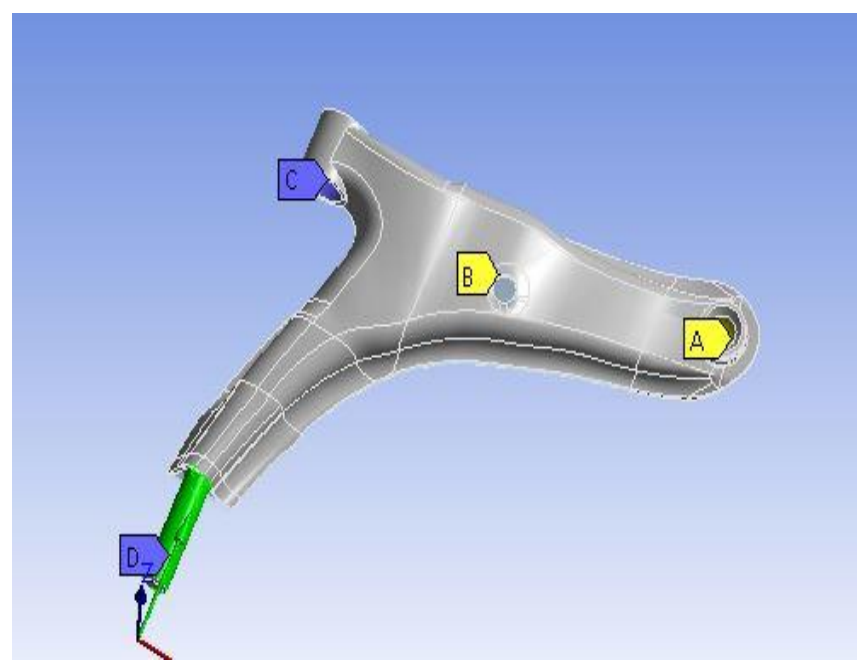

Fig 5.4.2 Loading Condition

\section{RESULTS}

Many features were analyzed like stress and displacement from FEM analysis and results that were found are given below,

\subsection{Stress Analysis}

In stress analysis of lower suspension arm subjected to high stress shown in figure 10. According to the methodology to safer the design stress induced in arm should be less than the yield strength of the material. The stress found from the analysis is $211.06 \mathrm{MPa}$.

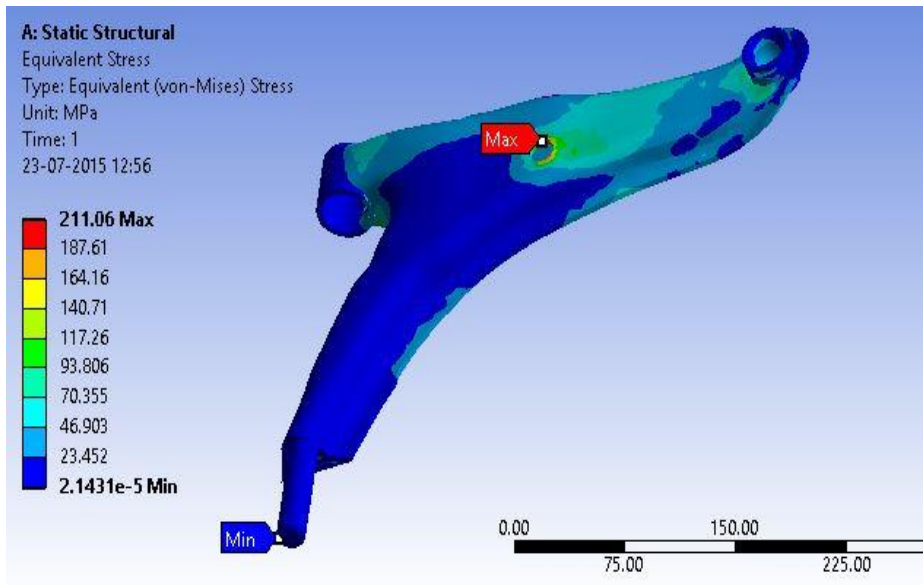

Fig 6.1 Equivalent Stress

\subsection{Total Deformation}

Total deformation shows that at what stage the component will deflect from its original position. Total deformation should be within the limits and Total deformation found in the analysis was $0.65515 \mathrm{~mm}$.

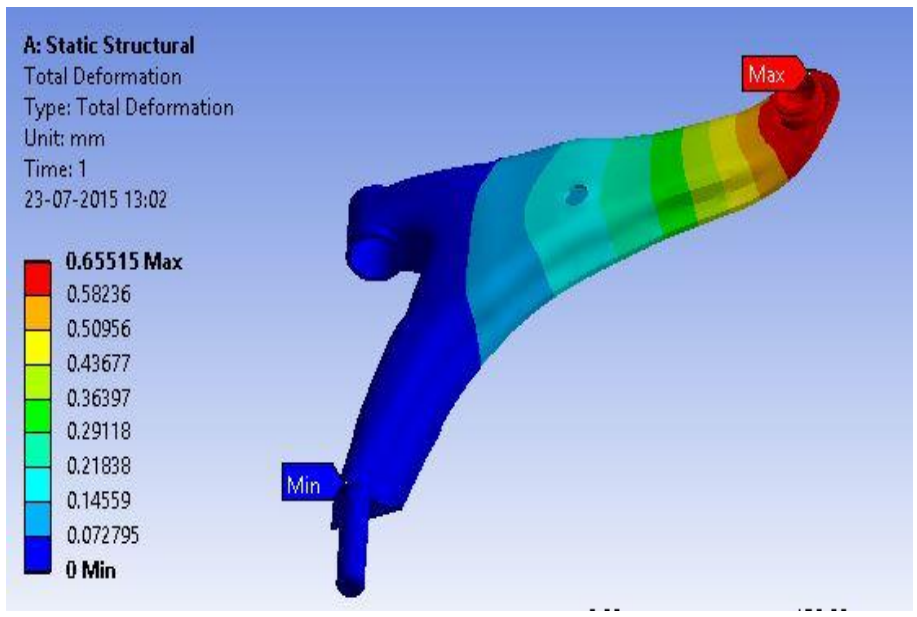

Fig 6.2 Total Deformation

Table 6

\begin{tabular}{|l|l|}
\hline Parameter & Results \\
\hline Equivalent stress & $211 \mathrm{MPa}$ \\
\hline Deformation & $0.65515 \mathrm{~mm}$ \\
\hline Safety Factor & 1.1845 \\
\hline
\end{tabular}

\section{CONCLUSION}

1. In stress analysis, the stresses of material for the given loading condition fall well in within the yield stress i.e. $211.06 \mathrm{MPa}$ as shown in figure 6.1.

2. The total deformation due to the force applied on the suspension arm was $0.65515 \mathrm{~mm}$ which is maximum was at the ball bearing of the suspension arm shown in figure 6.2

3. The minimum safety factor was 1.1845 which shows the component is safe. 


\section{REFERENCES}

[1]. M.M Rahman, K. Kadirgama, M.M. Noor, M.R.M.

Rejab, S.A. Kesulai, "Fatigue Life Prediction of Lower Suspension Arm Using Strain-Life Approach" European Journal of Scientific Research 2009

[2]. Dattatray Kothawale, Dr. Y.R. Kharde, "Analysis of Lower Control Arm in Front Suspension System Using FEA Approach" Internationals Journals of Engineering Research and Development 2013

[3]. Pratik S. Awati, Prof. L.M. Judulkar, "Modal and Stress Analysis of Lower Wishbone Arm Along With Topology" International Journal of Applications or Innovation in Engineering \& Management 2014

[4]. Vijaykumar V Solanki, Prof. N.S. Patel, "Static Analysis Geometric Optimization of Independent Suspension Link" International Journals of Thesis Projects and Dissertations 2014

[5]. Sagar Kailas Darge, Prof. S.C. Shilwant Swapnil, S

Kulkarni, "Review on Design and Evaluation of Suspension Arm for an Automobile Using Fem" International Journals Of Advance Engineering Research And Studies 2014

[6]. Prof. A.M. Patil, Prof. A.S. Todkar, Prof. R.S. Mithari, Prof. V.V. Patil," Experimental and Finite Element Analysis of Left Side Lower Wishbone Arm of Independent Suspension System" Journal of Mechanical and Civil Engineering 2013. 